\title{
$\beta$-Carotene: A Natural Compound Improves Cognitive Impairment and Oxidative Stress in a Mouse Model of Streptozotocin-Induced Alzheimer's Disease
}

\author{
Sundas Hira ${ }^{1}$, Uzma Saleem ${ }^{1,2, *(0)}$, Fareeha Anwar ${ }^{1, *(1)}$, Muhammad Farhan Sohail ${ }^{1}$, \\ Zohaib Raza ${ }^{1,2}$ and Bashir Ahmad ${ }^{1}$ \\ 1 Riphah institute of Pharmaceutical Sciences, Riphah International University, Lahore Campus, \\ Lahore 54000, Pakistan \\ 2 Faculty of Pharmaceutical Sciences, GC University, Faisalabad 38000, Pakistan \\ * Correspondence: uzma95@gmail.com (U.S.); Fareeha.anwar@riphah.edu.pk (F.A.); \\ Tel.: +92-333-490-4928 (U.S.); +92-333-888-3251 (F.A.)
}

Received: 12 July 2019; Accepted: 23 August 2019; Published: 2 September 2019

\begin{abstract}
Alzheimer's disease (AD) is a neurodegenerative disease characterized by a cascade of changes in cognitive, behavioral, and social activities. Several areas of the brain are involved in the regulation of memory. Of most importance are the amygdala and hippocampus. Antioxidant therapy is used for the palliative treatment of different degenerative diseases like diabetes, cirrhosis, and Parkinson's, etc. The objective of this study was to assess the effectiveness of exogenous antioxidants, in particular, $\beta$ carotene $(1.02$ and $2.05 \mathrm{mg} / \mathrm{kg}$ ) against intracerebroventricular injected streptozotocin-induced memory impairment in mice. Streptozotocin ( $3 \mathrm{mg} / \mathrm{kg}$, i.c.v) was administered in two separate doses (on 1st and 3rd days of treatment) for neurodegeneration. Fifty Albino mice (male) were selected in the protocol, and they were classified into five groups (Group I—control, Group II—disease, Group III—standard, Group IV-V- $\beta$-carotene-treated) to investigate the cognitive enhancement effect of selected antioxidants. The cognitive performance was observed following the elevated plus-maze, passive avoidance, and open field paradigms. Acetylcholine esterase, $\beta$-amyloid protein, and biochemical markers of oxidative stress such as glutathione peroxidase, superoxide dismutase, and catalase were analyzed in brain homogenates. In silico activity against acetylcholinesterase (AChE) was determined by the molecular modeling of $\beta$-carotene. $\beta$-carotene at a dose of $2.05 \mathrm{mg} / \mathrm{kg}$ was found to attenuate the deleterious effects of streptozotocin-induced behavioral and biochemical impairments, including the inhibition of acetylcholinesterase activity. The in silico studies confirmed the binding capacity of $\beta$-carotene with the acetylcholinesterase enzyme. The administration of $\beta$-carotene attenuated streptozotocin-induced cognitive deficit via its anti-oxidative effects, inhibition of acetylcholinesterase, and the reduction of amyloid $\beta$-protein fragments. These results suggest that $\beta$-carotene could be useful for the treatment of neurodegenerative diseases such as Alzheimer's disease.
\end{abstract}

Keywords: oxidative stress; $\beta$-carotene; dementia; acetylcholinesterase; biochemical markers

\section{Introduction}

Alzheimer's disease (AD) is a neurodegenerative disease characterized by a cascade of changes in cognitive, behavioral, and social activities [1]. Numerous neurotransmitters and neuromodulators imparting their role in cognition are acetylcholine, serotonin, GABA ( $\gamma$-aminobutyric acid), estrogen, neuropeptides, nitric oxide, endogenous antioxidants, and calcium [2]. Cholinergic transmission is involved in the severity of cognitive abilities [3]. Dwindled cholinergic function leads to cognitive impairments. Various anticholinesterase drugs are reported to alleviate AD by enhancing the 
acetylcholine concentration in the brain [4]. Acetylcholine (ACh) regulates many functions in the Central nervous system, such as alertness, wakefulness, and aggression [5]. ACh exerts its effect on the striatum, hippocampus, and amygdala [6]. The main regions of the brain involved in memory and learning processes are the basal forebrain and hippocampus [7]. Any distortion in the function or structure of these brain areas could cause cognitive impairment. The amygdala and hippocampus interact to regulate the memory system when emotions are involved [8]. These distortions lead to disruptions in the amyloid precursor protein (APP) metabolism and $\beta$-amyloid production that causes neurotoxicity [9]. Recent research indicated that the major contributing proteins in Alzheimer's are tau, $\beta$-amyloid, and neurofibrillary tangles [10]. Any deformities in APP and amyloid production or destruction lead the AD. Different therapies in clinical trials for the treatment of AD are anti-amyloid and anti-tau therapies [11]. Streptozotocin is a natural antibiotic and is toxic to cells. Intracerebroventricular administration of streptozotocin results in a cognitive deficit. It causes the aggregation of $A \beta$ and tau proteins and diminished cholinergic activity that is responsible for a cascade of pathological reactions leading to dementia. This cognitive decline may be associated with the reduced concentration of glycogen synthase kinase.

The free radical generation and oxidative damage theories suggest that oxidative stress promotes neurodegeneration that is related to Alzheimer's [12]. Oxidative damage occurs due to the disturbance between reactive oxygen species (ROS) generation and the body's ability to remove these ROS, as ROS could lead to tissue damage $[13,14]$. The brain areas such as the cerebral cortex and hippocampus that regulate cognitive and motor function are more vulnerable to oxidative stress and require antioxidants [15]. Another possible mechanism of neurodegeneration may be the inflammation of neurons, increased reactive oxygen species leading to oxidative damage, and biochemical modifications in the brain that ultimately lead to neuronal death [16].

Antioxidants could be exogenous or endogenous and perform various functions [17]. Antioxidants perform their function by acting as precursors, scavengers, or by removing oxygen species. They impart a role by inhibiting the synthesis of reactive oxygen species and by forming complexes with metal ions that are involved for the catalysis of reactive oxygen species generation [18]. There are two kinds of antioxidant systems present naturally in the body, i.e., various enzymes and antioxidants with low molecular weight (LMWA). The enzymes which act as antioxidants are glutathione, peroxidase, catalase, and superoxide dismutase [19]. The low molecular weight antioxidants (LMWA) are of two type's, i.e., direct and indirect-acting. Direct-acting LMWA are scavengers and chain-splitting antioxidants [20].

$\beta$-carotene belongs to the class of carotenoid hydrocarbons. $\beta$-carotene acts as an antioxidant due to its scavenger and quencher nature, as well as its synergistic effect with other antioxidants [21]. The current study was carried out to evaluate the effectiveness of $\beta$-carotene on cognitive performance by using behavioral paradigms and endogenous antioxidant markers because carotenoids possess $t$ antioxidant effects which armor against lipid peroxidation and oxidative stress.

\section{Materials and Methods}

\subsection{Materials}

$\beta$-Carotene, trichloroacetic acid solution, 5,5-dithio-bis-(2-nitrobenzoic acid) (DTNB) reagent, phosphate buffer solution, pyrogallol solution, dipotassium hydrogen phosphate, potassium hydroxide, potassium dihydrogen phosphate, hydrogen peroxide from Sigma Aldrich, Darmstadt, Germany and diazepam from Pfizer, Karachi, Pakistan. All chemicals were purchased from the local market.

\subsection{Experimental Animals}

Male mice $(n=50)$ were received from the Veterinary Research Institute (VRI), Lahore. All mice were almost two to three months old weighing $30-40 \mathrm{~g}$ at the start of the study. All animals were kept at Riphah International University for two weeks prior to the study under light/dark cycle, 
$45-55 \%$ humidity, and at a temperature of $22 \pm 2{ }^{\circ} \mathrm{C}$ for acclimatization. They were provided with water and food ad libitum. This study was carried out on animals after obtaining permission from the research ethical committee (REC) of Riphah International University with an authorized number of REC/RIPSLHR/2017/012 ruled under the regulation of the Institute of Laboratory Animal Resources, Commission on Life Sciences University, National Research Council (1996).

\subsection{Study Design}

They were categorized into five groups each containing 10 mice. Group I, II, and III served as the control group, disease group (streptozotocin $3 \mathrm{mg} / \mathrm{kg}$ i.c.v-intracerebroventricular injection), and standard (piracetam $200 \mathrm{mg} / \mathrm{kg}$. i.p.-intraperitoneally) groups, respectively. Group IV \& V served as treatment groups ( $\beta$-carotene at a dose of 1.02 and $2.05 \mathrm{mg} / \mathrm{kg}$, respectively).The dose of $\beta$-carotene was selected by considering the available human dose that is converted to the animal dose [22]. $\beta$-carotene was administered in the form of a suspension in CMC (Carboxy methyl cellulose). Streptozotocin (STZ) was administered i.c.v bilaterally in two divided doses (1st and 3rd day of treatment). The groups were given the treatment orally for fourteen consecutive days. On day 14, each animal was assessed for cognitive function.

\subsection{Evaluation of Cognitive Performance}

\subsubsection{Elevated Plus-Maze}

The apparatus used for the elevated plus-maze was made up of four arms, i.e., two open arms $(16 \times 5 \mathrm{~cm})$ and two closed arms $(16 \times 5 \times 12 \mathrm{~cm})$ that were extended from the central stage $(5 \times 5$ $\mathrm{cm}$ ) with a height of $25 \mathrm{~cm}$. On the fourteenth day, after one hour of administration of the oral dose, the animals were tested by placing each mouse at edge of open arm, facing away from central stage and the transfer latency was measured for $90 \mathrm{~s}$. The transfer latency is the time (s) the mice took to enter from the open arm into the closed arm. The retention of memory was measured by performing the same procedure on the 15th day (after $24 \mathrm{~h}$ ) [23].

\subsubsection{Passive Avoidance Apparatus}

The passive avoidance apparatus is made up of a box $(27 \times 27 \times 27 \mathrm{~cm})$. The box has four walls.

One wall is made up of Plexiglas and three wooden walls. A platform of wood $(10 \times 7 \times 1.7 \mathrm{~cm})$ is placed in middle of the floor. The floor is made up of $3 \mathrm{~mm} \mathrm{SS}$ - stainless steel rod each with a distance of $8 \mathrm{~mm}$. A 20 volts AC electric shock was applied to the floor. On the fourteenth day after one hour of administration of the oral dose, each experimental mouse was treated for their cognitive performance. The test was divided into three sessions (first, second, and retention sessions). In the first session, each experimental animal was placed onto the wooden platform and the step down latency was measured. The step down latency (SDL) is the time the animal took to step down with four paws from the platform to the floor. The experimental animal that had a SDL within 2-15 s was taken for the second and retention tests. After $90 \mathrm{~min}$ of the first test, another session was carried out. The animals with a SDL of more than $60 \mathrm{~s}$ were selected for the retention test. The retention test was performed after $24 \mathrm{~h}$ on the 15th day without electric shocks. The SDL was noted in the same manner as previously recorded. The cut-off time was $300 \mathrm{~s}$. An increased SDL was an indication of cognitive enhancement [24].

\subsubsection{Open Field Apparatus}

The open field apparatus is composed of a square field $(60 \times 60)$ with a white floor which is segregated into 36 squares $(10 \times 10)$ enclosed by a black Plexiglass wall $(25 \mathrm{~cm}$ high). A red light is positioned over its center to illuminate the field. The 20 squares which are adjacent to the wall are named as the "field periphery". The field periphery represents a protected field and the remaining 16 squares represent an "exposed field" or field center. 
On day 14, after one hour of administration of the oral dose, test was conducted during the first half of the dark phase of the light/dark cycle. Each mouse was placed in the center allowing it to move freely across the entire field for $5 \mathrm{~min}$ [25].

To examine the cognitive performance, different parameters of the open field were classified as follows;

Behavior

A. Whole or major body movement

1. Type of movement

a. Latency (Initial time taken by the mice to leave the start area)

b. Freezing (Time spent by the mice without any movement)

c. Rearing

2. Part body Movement

a. Scratching/Grooming

Location

a. Field area visited (central and peripheral)

b. Crossing

Autonomic Nervous System (ANS)

i. Urination

ii. Defecation [26].

\subsection{Neurochemical Studies}

\subsubsection{Estimation of Reduced Glutathione (GSH)}

A total of $1 \mathrm{~mL}$ of brain homogenate was taken and it was precipitated with $1 \mathrm{~mL}$ of $10 \%$ trichloroacetic acid (TCA). Then, $0.5 \mathrm{~mL}$ of DTNB reagent $(0.1 \mathrm{mM})$ and $4 \mathrm{~mL}$ of phosphate solution were mixed with an aliquot of supernatant. The sample mixture was examined under a UV spectrophotometer at $412 \mathrm{~nm}$.

The following Equation was used for the measurement of glutathione peroxidase:

$$
\mathrm{GSH}=\mathrm{Y}-0.00314 / 0.034 \times \mathrm{DF} / \mathrm{BT} \times \mathrm{VU}
$$

In the above equation, DF denotes dilution factor that is $1, \mathrm{VU}$ represents aliquot volume, $\mathrm{Y}$ is the absorbance, and BT $=$ Brain tissue homogenate [27].

\subsubsection{Estimation of Oxidized Glutathione (GSSG)}

A total of $1 \mathrm{~mL}$ of tissue homogenate was mixed with reaction buffer consisting of $0.1 \mathrm{mM}$ of DTNB, $0.5 \mathrm{mM}$ of NADPH, and $2 \mathrm{mM}$ of GSSG. The rate of DTNB reduction was monitored for $5 \mathrm{~min}$ at $25^{\circ} \mathrm{C}$ by a spectrophotometric method at $412 \mathrm{~nm}$. The blank contained all except GSSG [28]. The standard curve was used for the estimation of GSSG levels:

$$
\mathrm{Y}=0.0174 \mathrm{X}+0.0023
$$

GSSG/GSH redox ratios were determined by dividing the GSSG values by the GSH levels [29]. 


\subsubsection{Determination of Superoxide Dismutase (SOD)}

A reaction mixture $(3 \mathrm{~mL})$ was made by adding $0.1 \mathrm{~mL}$ of tissue homogenate, $0.1 \mathrm{~mL}$ of pyrogallol solution $(1 \mathrm{M})$, and $2.8 \mathrm{~mL}$ of potassium phosphate buffer $(\mathrm{pH} 7.4$ and $0.1 \mathrm{M})$. The sample was analyzed at a wavelength of $312 \mathrm{~nm}$ [30].

The regression equation of SOD is as follows:

$$
\mathrm{Y}=0.0095 \mathrm{x}+0.1939
$$

\subsubsection{Estimation of CAT}

A total of $1.95 \mathrm{~mL}$ of phosphate buffer $(\mathrm{pH} 7,50 \mathrm{mM})$ and $1 \mathrm{~mL} \mathrm{H}_{2} \mathrm{O}_{2}$ solution $(30 \mathrm{mM})$ were mixed with $0.05 \mathrm{~mL}$ of tissue homogenate to note the absorbance of Catalase which was estimated by using the following formula:

$$
\mathrm{CAT}=\delta \mathrm{O} . \mathrm{D} \div \mathrm{E} \times \text { Volume of sample }(\mathrm{mL}) \times \operatorname{protein}(\mathrm{mg})
$$

$\delta \mathrm{O} . \mathrm{D}$ represents the change in absorbance per minute, E symbolizes the extinction coefficient of $\mathrm{H}_{2} \mathrm{O}_{2}$ with a value $0.071 \mathrm{mmol} \mathrm{cm}{ }^{-1}$ [31]. The Lowery method was followed to measure the protein contents [32]. The regression line followed to estimate the contents of protein was as follows:

$$
\mathrm{Y}=0.00007571 \mathrm{x}+0.0000476
$$

\subsubsection{Determination of Acetylcholinesterase Activity}

A total of $2.6 \mathrm{ml}$ phosphate buffer $(\mathrm{pH}=8)$ and $100 \mu \mathrm{L}$ of DTNB reagent $(0.1 \mathrm{mM})$ was added to $0.4 \mathrm{~mL}$ of tissue homogenate. The absorbance was noted at $412 \mathrm{~nm}$. The initial reading was noted when the absorbance of the constituents stabilized. Then, $20 \mu \mathrm{L}$ of acetylthiocholineiodide $(1 \mathrm{mM})$ (substrate) was mixed with the contents of the cuvette and the absorbance was noted for 10 min every $20 \mathrm{~min}$. The mean change in absorbance was calculated by using the following formula:

$$
\mathrm{R}=5.74 \times 10^{-4} \times \mathrm{A} / \mathrm{Co}
$$

$\mathrm{A}=$ change in absorbance per minute.

Rate of moles of acetylthiocholiniodide hydrolyzed per min/gm of brain tissue.

$\mathrm{C}_{\mathrm{o}}=$ Original concentration [33].

\subsection{Protein Analysis by ELISA}

An ELISA kit was used for the determination of $A \beta 1-40$ and $A \beta 1-42$ levels in the brain tissues of mice. $A \beta 1-40$ and $A \beta 1-42$ were combined with HRP-horseradish peroxidase enzyme to make the antigen-antibody-enzyme-antibody complex. After that, TBM (3,3',5, $5^{\prime}$-tetramethylbenzidine) solution was added. This reaction was stopped by the addition of sulfuric acid. The change in color was observed at $450 \mathrm{~nm}$ spectrophotometrically. The concentrations of $\mathrm{A} \beta 1-40$ and $\mathrm{A} \beta 1-42$ were quantified by comparing the optical densities of the samples to the standard [34].

\subsection{In Silico Modeling}

$\beta$-carotene was computationally modeled to predict its modulatory behavior on acetylcholinesterase (AChE) via docking in Autodock Vina 1.1.2 [35]. The three dimensional (3D) conformers of $\beta$-carotene (CID: 5280489) and Piracetam (CID: 4843) were retrieved from Pubchem database and saved as PDB - protein data bank formats using Open Babel Package 2.3.1 [36]. The crystallized structure of AChE (PDB ID: 2C5G, $1.95 \AA$ ) was retrieved from the (RSCB = Research Collaboratory for Structural Bioinformatics) protein data bank (https://www.rcsb.org/). The high-energy atomic conformational strains were minimized by CHARMm (Chemistry at HARvard Macromolecular Mechanics )forcefield with the 
MMFF94 partial charge method to optimize the structures of ligands and AChE in Accelrys discovery studio visualizer v17.2 [37]. The rigid protein was prepared for flexible ligands in Autodock tools 1.5.6. The polar hydrogens were added, and non-polar hydrogen was merged to optimize the tautomeric and ionization states of protein residues. The search space was defined by $40 * 40 * 40(x, y, z)$ dimensions of a grid box volume with $1 \AA$ grid point spacing and centered to $4.61932 * 65.9682 * 55.4541(x, y, z)$ coordinates. The binding energy $(\Delta \mathrm{G})$ of the ligand to protein was estimated by the scoring function of the Autodock Vina 1.1.2. The accuracy of the docking protocol to predict the global conformational minimum was validated by re-docking of crystallized ligand (i.e., thiocholine) of 2C5G and the comparison with its apo conformation. Docking was performed in triplicates for each ligand and binding posed with the lowest binding energy was considered to calculate the inhibition constant (Ki) (5). These binding conformations were further utilized to analyze the interactions of the ligand-protein complex using Accelrys discovery studio visualizer v17.2.

\subsection{Statistical Analysis}

All the results were represented as mean \pm SEM $(n=10)$ by using the Graph Pad Prism software version 5, San Diego, CA, USA. The parametric test was applied to the animal behavioral analysis. Data described in Tables 1 and 2 were analyzed by applying the one way ANOVA. $p \leq 0.05, p \leq 0.01$, and $p \leq 0.001$ were considered as significant $\left({ }^{*}\right)$, moderately significant $\left({ }^{* *}\right)$, and highly significant $\left({ }^{* * *}\right)$, respectively, compared to the disease group.

\section{Results}

\subsection{Evaluation of Cognitive Performance}

3.1.1. The Effect of $\beta$-Carotene on the Transfer Latency Using the Elevated Plus Maze Model in Mice that Received i.c.v STZ

Cognitive performance was assessed by following the elevated plus maze paradigm. The animals were subjected to transfer latency evaluation on the 15th day. Figure 1 clearly indicated that animals that received $\beta$-carotene $(1.02$ and $2.05 \mathrm{mg} / \mathrm{kg})$ caused highly significant $(p \leq 0.001)$ variation of transfer latency (TL) in mice compared to the diseased control group.

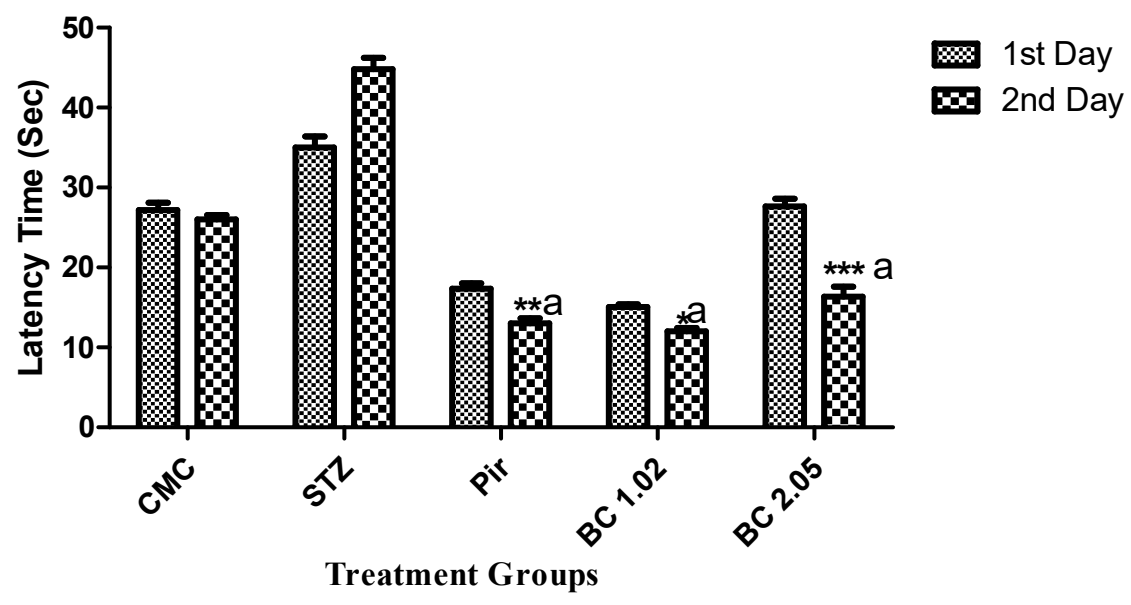

Figure 1. Effect of $\beta$-carotene on the transfer latency using the elevated plus maze model in mice that received i.c.v STZ-streptozotocin. Data are represented as mean $\pm \mathrm{SEM}, \mathrm{n}=10,{ }^{\mathrm{a}} P<0.05$. Significance was given in comparison to the disease group and $p<0.05^{*}, 0.01^{* *}, 0.001^{* * *}$ was given when compared with day one. STZ $=$ Streptozotocin, Pir $=$ Piracetam, $B C=\beta$-carotene. 
3.1.2. Effect of $\beta$-Carotene on the Step Down Latency Using the Passive Avoidance Model in Mice that Received i.c.v STZ

The passive avoidance model has been used to examine the long-term memory based on the step down latency. It was clear from Figure 2 that the mice treated with $\beta$-carotene $(1.02$ and $2.02 \mathrm{mg} / \mathrm{kg})$ showed moderately significant $(p \leq 0.01)$ improvement in cognitive performance.

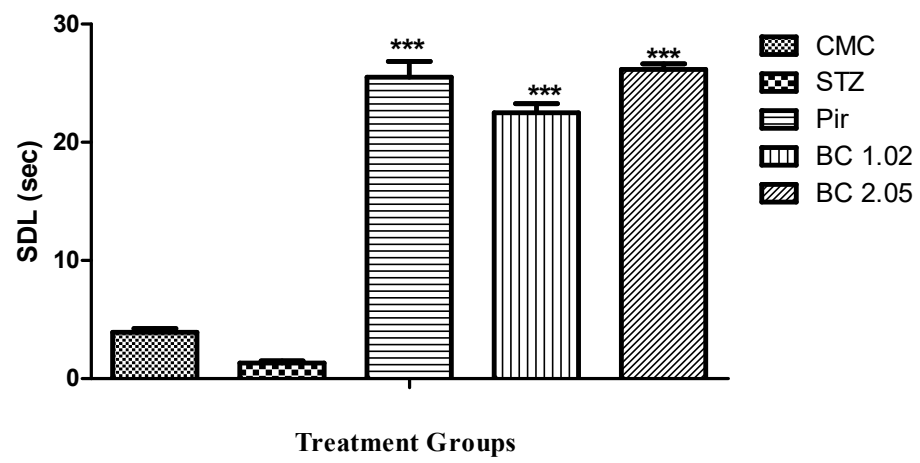

Figure 2. Effect of $\beta$-carotene on the step down latency using the passive avoidance model in mice that received i.c.v STZ. Data are represented as mean $\pm S E M, n=10$. Significance was given in comparison to the disease group. ${ }^{* *} P<0.001$ was given in comparison to disease group.

\subsubsection{The Effect of $\beta$-Carotene Following the Open Field Paradigm in Mice that Received i.c.v STZ}

Different parameters such as whole body movement, partial body movement, location, and ANS are observed with the help of the open field paradigm. Table 1 revealed that $\beta$-carotene $(2.05 \mathrm{mg} / \mathrm{kg})$ showed highly significant improvement $(p \leq 0.001)$ in freezing, central, and peripheral area visited, defecation, and urination. Low-dose $\beta$-carotene $(1.02 \mathrm{mg} / \mathrm{kg})$ showed moderately significant $(p \leq 0.01)$ improvement in rearing and highly significant improvement in all other parameters.

Table 1. The effect of $\beta$-carotene following the open field paradigm in mice that received i.c.v STZ.

\begin{tabular}{|c|c|c|c|c|c|c|}
\hline \multicolumn{3}{|c|}{ Parameters } & Control & Disease (STZ) & \multicolumn{2}{|c|}{$\beta$-Carotene } \\
\hline \multicolumn{3}{|c|}{ Dose mg/kg } & CMC 1 mL/kg & 3.0 & 1.02 & 2.05 \\
\hline \multirow{3}{*}{$\begin{array}{l}\text { Whole body } \\
\text { movement }\end{array}$} & \multirow{3}{*}{\multicolumn{2}{|c|}{$\begin{array}{l}\text { Latency (s.) } \\
\text { Rearing (no.) } \\
\text { Freezing (s.) }\end{array}$}} & $2.80 \pm 0.374$ & $5.6 \pm 0.510$ & $3.20 \pm 0.200$ & $2.00 \pm 0.316$ \\
\hline & & & $27.40 \pm 1.030$ & $16.60 \pm 0.245$ & $39.60 \pm 1.435^{* *}$ & $29.80 \pm 9.749$ \\
\hline & & & $32.00 \pm 1.225^{* * *}$ & $89.00 \pm 3.317$ & $29.00 \pm 1.789^{* * *}$ & $16.00 \pm 2.258^{* * *}$ \\
\hline \multirow{3}{*}{$\begin{array}{l}\text { Part body } \\
\text { Movement }\end{array}$} & \multirow{3}{*}{\multicolumn{2}{|c|}{$\begin{array}{l}\text { Scratching (s.) } \\
\text { Teeth Chattering } \\
\text { Digging }\end{array}$}} & $3.80 \pm 0.97^{* * *}$ & $5.40 \pm 0.400$ & $2.60 \pm 0.400^{* * *}$ & $1.20 \pm 0.490$ \\
\hline & & & No & Yes & No & No \\
\hline & & & No & Yes & No & No \\
\hline \multirow{2}{*}{ Location } & Field area & Central (s.) & $52.40 \pm 7.019 * * *$ & $112.00 \pm 16.778$ & $30.20 \pm 1.985^{* * *}$ & $30.00 \pm 3.146^{* * *}$ \\
\hline & Visited & Peripheral (s.) & $209 \pm 9.066^{* * *}$ & $88.00 \pm 3.742$ & $235.0 \pm 2.236^{* * *}$ & $250.080 \pm 15.203^{* * *}$ \\
\hline \multirow{3}{*}{ ANS } & \multicolumn{2}{|c|}{ Crossing (no.) } & $31.60 \pm 0.927^{* * *}$ & $16.30 \pm 0.200$ & $49.40 \pm 631^{* * *}$ & $16.00 \pm 1.342^{* * *}$ \\
\hline & \multicolumn{2}{|c|}{ Defecation (no.) } & $2.60 \pm 0.670 * * *$ & $17.00 \pm 0.447$ & $0.60 \pm 0.400^{* * *}$ & $0.400 \pm 0.245^{* * *}$ \\
\hline & \multicolumn{2}{|c|}{ Urination (no.) } & $4.6 \pm 0.400^{* * *}$ & $10.00 \pm 0.707$ & $0.80 \pm 0.374^{* * *}$ & $0.200 \pm 0.200 * * *$ \\
\hline
\end{tabular}

Data are represented as mean $\pm \mathrm{SEM}, \mathrm{n}=10$. $\left({ }^{* *} P<0.01\right),\left({ }^{* * *} P<0.001\right)$ Significance was given in comparison to the disease group.

\subsection{Determination of Biochemical Markers in Brain Tissues of Mice that Received I.STZ}

Biochemical markers such as GSH, SOD, CAT, and acetylcholinesterase activity were determined to estimate the efficacy of selected antioxidants in oxidative stress. GSSG/GSH ratio was also estimated. Results indicated significantly increased levels of all antioxidant enzymes and decreased acetylcholinesterase activity of the treated groups as compared with the diseased control group (Table 2). GSSG/GSH ratio was significantly decreased in all treated groups when compared with diseased group (Figure 3). 
Table 2. The determination of biochemical markers in brain tissues of mice that received i.c.v STZ.

\begin{tabular}{|c|c|c|c|c|c|c|}
\hline Sr. \# & $\begin{array}{l}\text { Treatment } \\
\text { Groups }\end{array}$ & $\begin{array}{l}\text { Dose } \\
(\mathrm{mg} / \mathrm{kg})\end{array}$ & $\begin{array}{c}\text { GSH } \\
(\mu \mathrm{g} / \mathrm{mg} \text { of Brain } \\
\text { Tissue })\end{array}$ & $\begin{array}{c}\text { SOD } \\
(\mu \mathrm{g} / \mathrm{mg} \text { of Brain } \\
\text { Tissue) }\end{array}$ & $\begin{array}{c}\text { CAT } \\
\text { ( } \mu \mathrm{g} / \mathrm{mg} \text { of } \\
\text { Brain Tissue })\end{array}$ & $\begin{array}{c}\text { Acetylcholine } \\
\text { Esterase } \\
\text { ( } \mu \mathrm{mol} / \mathrm{mg} \text { of } \\
\text { Brain Tissue) }\end{array}$ \\
\hline 1 & Control & $\begin{array}{c}\mathrm{CMC} \\
(1 \mathrm{~mL} / \mathrm{kg})\end{array}$ & $14.4 \pm 1.03^{* * *}$ & $10.320 \pm 0.185^{* * *}$ & $4.96 \pm 0.163^{* * *}$ & $2.8 \pm 0.170^{* * *}$ \\
\hline 2 & $\begin{array}{l}\text { Diseased } \\
\text { (STZ) }\end{array}$ & 300 & $3.54 \pm 0.383$ & $0.043 \pm 0.002$ & $1.11 \pm 0.206$ & $7.54 \pm 0.220^{* * *}$ \\
\hline 3 & $\begin{array}{l}\text { Standard } \\
\text { (Piracetam) }\end{array}$ & 200 & $9.40 \pm 0.678^{* * *}$ & $0.262 \pm 0.020$ & $4.93 \pm 1.00^{* * *}$ & $4.620 \pm 0.206^{* * *}$ \\
\hline 4 & $\beta$-carotene & $\begin{array}{l}1.02 \\
2.05\end{array}$ & $\begin{array}{c}10.30 \pm 0.200^{* * *} \\
10.320 \pm 0.185^{* * *}\end{array}$ & $\begin{array}{l}0.284 \pm 0.012 \\
0.492 \pm 0.012\end{array}$ & $\begin{array}{l}6.15 \pm 0.01^{* * *} \\
6.84 \pm 0.01^{* * *}\end{array}$ & $\begin{array}{l}3.430 \pm 0.187^{* * *} \\
3.380 \pm 0.080^{* * *}\end{array}$ \\
\hline
\end{tabular}

Data are represented as mean $\pm S E M, n=10 .{ }^{* * *} P<0.001$ Significance was given in comparison to the disease group.

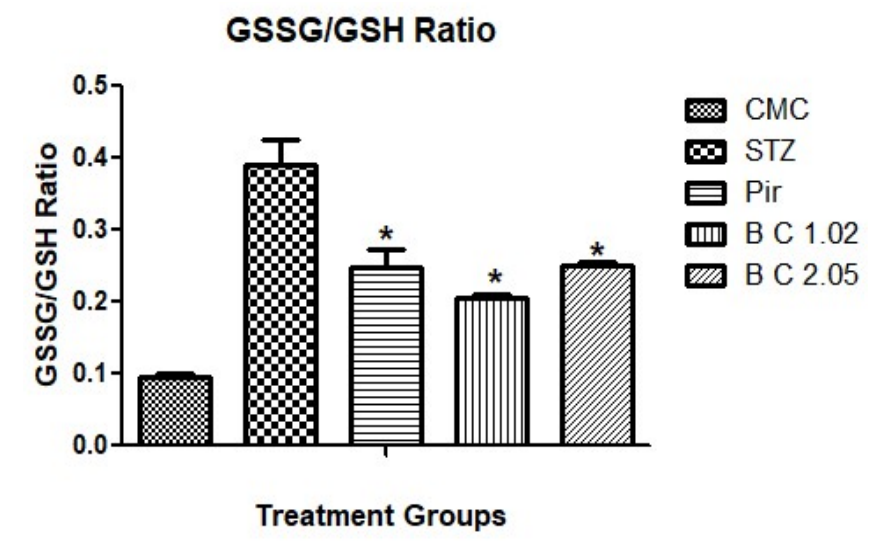

Figure 3. GSSG/GSH ratio of the treated groups. Data are presented as mean $\pm \mathrm{SEM}, \mathrm{n}=10,{ }^{*} p<0.05$ as compared to the disease group (STZ).

\subsection{Protein Analysis by ELISA}

$\beta$-amyloid estimation by the ELISA kit method indicated that $\beta$-carotene significantly reduced the levels in the mouse brain. This reduction might be due to less aggregation and plaque formation in the brain (Figure 4).
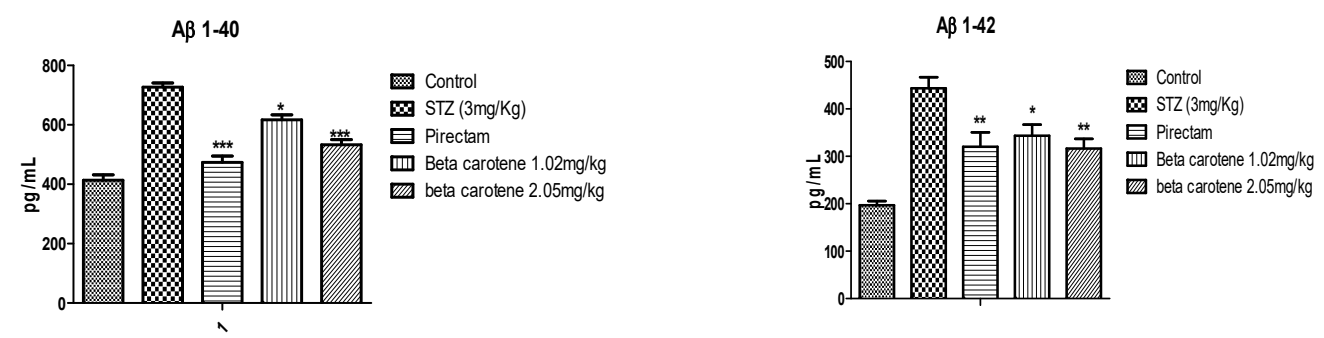

Figure 4. Total $A \beta 1-40$ and $A \beta 1-42$ levels extracted from the mouse brain. ${ }^{*} P<0.05,{ }^{* *} P<0.01$ and *** $P<0.001$ Significance was given in comparison to the disease group.

\subsection{In Silico Modeling}

The molecular modeling of $\beta$-carotene was performed to support its in-vitro activity against acetylcholine esterase (AChE). The re-docking of the flexible crystallized ligand validated the credibility of the results generated by the employed docking protocol. The re-docking simulation provided a binding conformation quite similar to the apo-conformation of the native ligand with $0.4129 \AA$ of root mean square deviation (RMSD) at the active site (Figure 4). The binding conformation of the re-docking also preserved the conserved interactions of the apo conformation with PHE330, TRP84, HIS440, and GLU199 protein residues at the catalytic site. 
Following the validation, $\beta$-carotene was simulated as a test ligand in the docking protocol with Piracetam as a standard. The lowest binding energy $(\Delta G)$ served as a function of higher affinity towards the protein (i.e., AChE-acetylcholine esterase). The docking simulation of Piracetam indicated the $-5.8 \mathrm{kcal} / \mathrm{mol}$ of binding energy $(\Delta \mathrm{G})$ as a measure of its binding affinity towards AChE to inhibit its activity with $56.05 \mu \mathrm{M}$ of inhibition constant (Ki). However, the binding affinity of $\beta$-carotene was found to exceed the standard threshold with $-7.7 \mathrm{kcal} / \mathrm{mol}$ of binding energy $(\Delta \mathrm{G})$ and superior $2.27 \mu \mathrm{M}$ inhibitions constant as compared to Piracetam. The key parameters of the docking simulation for these ligands have been tabulated (Table 3) that accounts for their potency towards AChE.

The binding energy of Piracetam was found to be distributed into energy components of hydrogen bonding and hydrophobic interactions at the catalytic site. On the other hand, $\beta$-carotene predominantly interacts with $\mathrm{AChE}$ by hydrophobic interactions that may account as a sole energy component of its binding energy (Figure 5). However, $\beta$-carotene shares the higher hydrophobic interactions with AChE as compared to Piracetam that exceeds the binding energy contribution of both energy components of Piracetam at the catalytic site.

The inhibitory potential of Piracetam was found to be consistent with its interaction to conserved PHE330, TRP84, and GLU199 protein residues of thiocholine at the catalytic site of AChE. In addition, its pyrrolidine and acetamide moieties were also involved in the hydrogen binding to GLY441, SER200, GLY118, and TYR130. Comparatively, $\beta$-carotene exhibited the distinct modulatory behavior by hydrophobic interactions with unique LEU456, LEU450, LEU127, MET83, VAL71, and MET90 protein residues of $\mathrm{AChE}$ as compared to the conserved residues of the catalytic site (Figure 6).

Table 3. Binding affinity, inhibition constant, and interactions of the test and standard with AChE.

\begin{tabular}{ccccc}
\hline Compound & $\begin{array}{c}\text { Binding Energy } \\
(\boldsymbol{\Delta} \mathbf{G}) \mathbf{k c a l} / \mathbf{m o l}\end{array}$ & $\begin{array}{c}\text { Inhibition } \\
\text { Constant (Ki) } \boldsymbol{\mu M}\end{array}$ & Interacting Residues & Interaction Type \\
\hline B-carotene & -7.7 & 2.27 & $\begin{array}{c}\text { LEU456, LEU450, LEU127, } \\
\text { MET83, VAL71, MET90 }\end{array}$ & Alkyl \\
& & & TYR130, GLY118, GLU199, & \\
Piracetam & -5.8 & 56.05 & SER200, GLY441, TRP84, & H-Bonding, Alkyl \\
& & & PHE330 & \\
\hline
\end{tabular}
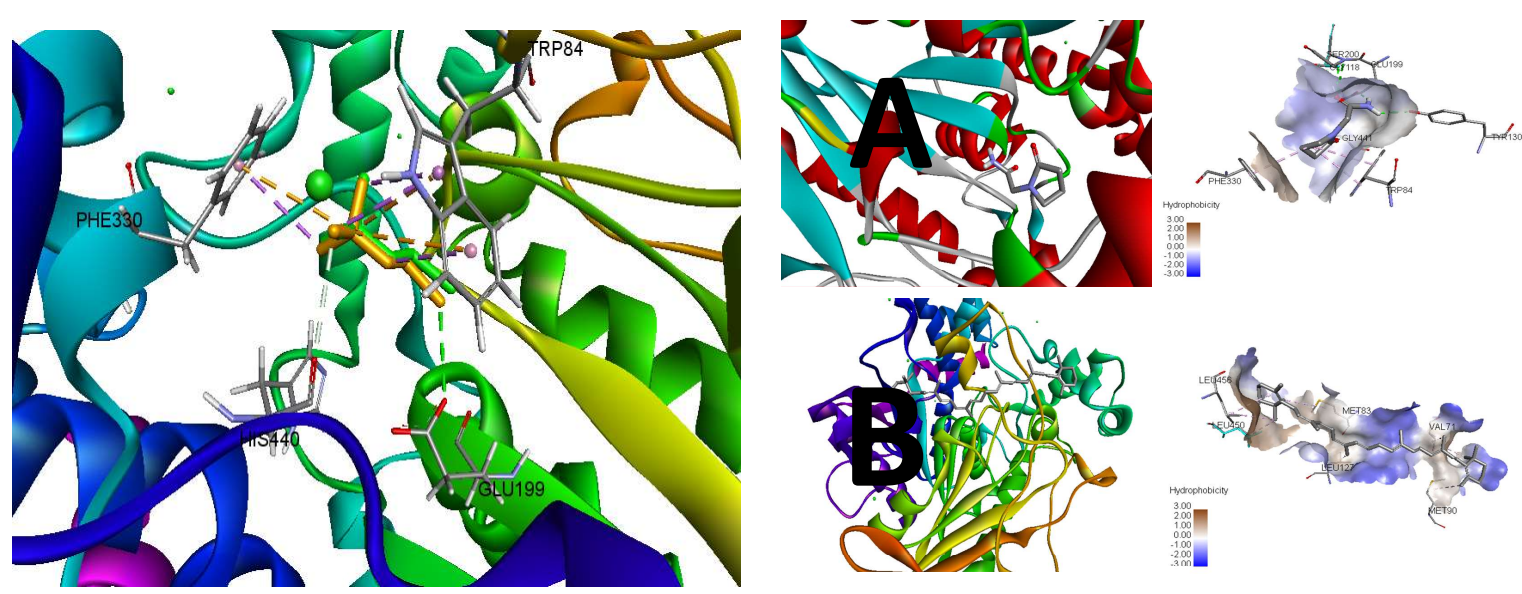

Figure 5. Re-docking of the flexible crystallized ligand for comparative conformational alignment with respect to the apo conformation. Best binding mode simulated (Left) and the pattern of hydrophobic interactions (Right) of Piracetam (A) and $\beta$-carotene (B) at the active site of AChE. 


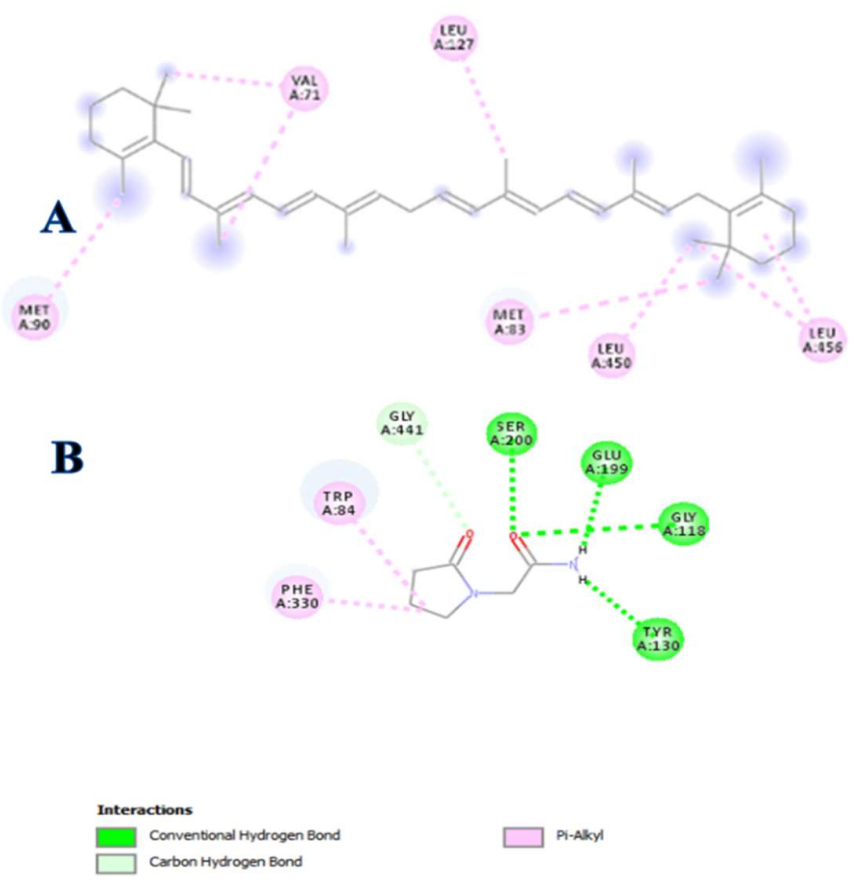

Figure 6. Two-dimensional (2D) plot of Piracetam (B) and $\beta$-carotene (A) binding interactions with residues of $\mathrm{AChE}$ active site.

\section{Discussion}

Cognitive impairment is a broad term related to many neurodegenerative diseases such as Alzheimer's. Present research work was carried out to evaluate the antioxidant potential in streptozotocin-induced memory impairment in experimental animals.

It is evident from previous studies that oxidative stress has a critical role in neurodegenerative disorders. Oxidative stress causes the release of glucocorticoids from adrenal glands, which is attributed to damage of the neurons and the impairment of memory [38]. Oxidative stress occurred due to the imbalance between ROS generation and the body's ability to remove these ROS, as ROS can lead to tissue damage that has been a suggested mechanism for cognitive impairment due to normal aging and neurodegenerative diseases [39]. The antioxidant's potential to improve cognition depends upon its ability to reach the brain [40].

Endogenous antioxidant levels revealed a greater increase in GSH, SOD, and CAT after treating the groups with exogenous antioxidants, such as $\beta$-carotene that had received i.c.v streptozotocin.

It is well established that the levels of GSH, CAT, and SOD were decreased in diseased animals leading to oxidative damage. It may be possible that i.c.v STZ could lead to the production of ROS, such as superoxides that are ultimately responsible for brain damage. Superoxides lead to reduced concentrations of glutathione. Glutathione (GSH) is the only defense that is available in mitochondria to metabolize hydrogen peroxide [41].

GSH reduction may be due to increased utilization, decreased formation, or increased metabolism of GSH [42]. Glutathione has a vital role in the management of oxidative stress and maintain the normal homoeostasis [43]. The GSSG/GSH ratio is a good indicator for monitoring the antioxidant intervention efficacy [29]. The same has been found in the present study as the ratio decreased significantly in Pirecetam, beta carotene 1.02 and 2.05 groups when compared with the STZ-treated animals. Administration of i.c.v STZ results in oxidative stress. Superoxide is most common among all free radicals that are generated during oxidative phosphorylation. When molecular oxygen is converted to water during normal cell metabolism, reactive oxygen species are produced (ROS). These ROS are superoxide, hydroxyl, and hydrogen peroxide radicals. Catalases degrade $\mathrm{H}_{2} \mathrm{O}_{2}$ into water [44]. 
SOD is considered to be the first-line of defense against free radicals. The increased concentration of SOD was found in $\beta$-carotene-treated mice, which may relate to the reversal of cognitive impairment caused by oxidative damage. The reduced level of SOD in diseased mice may relate the aggressiveness with oxidative damage due to stress. The cognitive enhancement effects may be attributed to the increased levels of endogenous antioxidants by reducing the oxidative stress [45].

Decreased energy metabolism or oxidative stress causes cognitive impairment by inhibition of ATP and acetyl-CoA synthesis that ultimately results in cholinergic deficiency. This cholinergic deficiency is primarily due to the increased activity of cholinesterase activity in the brain and decreased cholinecacetyl transferase activity in the hippocampus of i.c.v STZ mice [46]. Antioxidants have been the main therapeutic agents for several neurodegenerative diseases [47]. Acetylcholine owes to its excitatory effect causes the contraction of muscles and the secretion of hormones and regulates many functions in the CNS, such as alertness, wakefulness, and in aggression [5]. ACh has a vital role in improving cognitive function. The acetylcholine release is dynamic in different neural regions. ACh exerts its effect on the striatum, hippocampus, and amygdala. These three neural systems are involved in cognitive function. The release of $\mathrm{ACh}$ has a vital role in modulating the balance between the various neural systems during the training process, ACh releases immediately in the hippocampus earlier in the training process; however, Ach release is slower in the striatum and is involved in the extensive training [48,49]. Amyloid $\beta$ protein $(\mathrm{A} \beta)$ aggregation and plaque formation are the principal biomarkers for the detection of Alzheimer's disease. The most abundant form of $\mathrm{A} \beta$ protein in Alzheimer's is $A \beta 1-40$ and $A \beta 1-42$ [50]. Among two $A \beta 1-42$ had special importance in Alzheimer's disease as it is early deposited as a plaque form in Alzheimer [34]. Investigation of these isoforms of $\beta$-amyloid proteins showed significant reduction in the mice brains treated with $\beta$-carotene. Following experimental studies, the computational studies were performed to explain the AChE inhibitory potential of $\beta$-carotene. The molecular docking is widely used to predict the binding affinity and simulate the ligand-target complex orientations and interactions to provide the structural insights into the mechanism of action of ligand to modulate the target activity. In this study, a reliable docking protocol was adopted to provide the insights into the mechanism of action of $\beta$-carotene to inhibit the AChE activity with reference to Piracetam as a standard. Comparatively, the $\beta$-carotene exhibited the superior binding affinity with the lowest binding energy $(\Delta G)$ and inhibition constant (Ki). The hydrophobic energy components of $\beta$-carotene oriented it with the lowest binding energy as compared to hydrogen bonding and hydrophobic energy components for Piracetam. $\beta$-carotene is hydrophobic in nature with no hydrogen bond donor and acceptor on its skeleton that may justify its binding energy solely relying on hydrophobic interactions. Moreover, this hydrophobic behavior may suggest its repulsion from active site polar components involved in hydrogen bonding and subsequent diversion from conserved active site residues to form the interactions with unique residues. Therefore, these structural insights can reasonably justify the allosteric behavior of $\beta$-carotene to modulate the activity of AChE. For new drug discovery, the popularity of in silico modeling techniques is increasing day by day. This computational approach can facilitate the researcher for finding the new drug candidates against selected targets. $\beta$-carotene is effective naturally occurring antioxidant. Due to its antioxidant property, it may have the ability to treat neurodegeneration-related disorders. This study has been evaluated for its binding capability as a ligand to acetylcholinesterase enzyme. The decreased concentration of this enzyme in $\beta$-carotene-treated mice as compared to the diseased group may relate with the anti-Alzheimer's effect and support in silico profiling of $\beta$-carotene against the acetylcholinesterase enzyme [51,52].

\section{Conclusions}

The administration of $\beta$-carotene in STZ-induced cognitive deficit mice prevented the decrease in ACh concentration by inhibiting the acetylcholinesterase enzyme. Reduced plaques of $\beta$-amyloid protein in brains of $\beta$-carotene-treated mice also indicated the improvement of cognitive function. In silico studies also confirmed the binding capability of $\beta$-carotene with the acetylcholine esterase 
enzyme. Thus, $\beta$-carotene could be useful for memory enhancement and suggests its potential in the treatment of many neurodegenerative diseases such as Alzheimer's disease. Although this study did not estimate the effect of $\beta$-carotene on tau phosphorylation, which is an important consideration for Alzheimer's pathogenesis. Future studies are required to be conducted for molecular pathogenesis and treatment of Alzheimer's. Moreover, the excessive intake of $\beta$-carotene is associated with reversible carotenemia.

Author Contributions: S.H. and F.A. carried out the research and collected the data and wrote the manuscript, U.S. and B.A. conceptualized and supervised the study, Z.R. and M.F.S. did the bioinformatics part and formally analyzed the data.

Funding: The author(s) received no financial support for the research, authorship, and/or publication of this article.

Acknowledgments: No funding is granted for this research. All the financial need fulfilled by the authors.

Conflicts of Interest: All authors had no conflict of interest regarding this manuscript.

\section{References}

1. Rajesh, V.; Riju, T.; Venkatesh, S.; Babu, G. Memory enhancing activity of Lawsonia inermis Linn. leaves against scopolamine induced memory impairment in Swiss albino mice. Orient. Pharm. Exp. Med. 2017, 17, 127-142. [CrossRef]

2. Mothet, J.P.; Rouaud, E.; Sinet, P.-M.; Potier, B.; Jouvenceau, A.; Dutar, P.; Videau, C.; Epelbaum, J.; Billard, J.M. A critical role for the glial-derived neuromodulator d-serine in the age-related deficits of cellular mechanisms of learning and memory. Aging Cell 2006, 5, 267-274. [CrossRef] [PubMed]

3. Giovannini, M.; Casamenti, F.; Bartolini, L.; Pepeu, G. The brain cholinergic system as a target of cognition enhancers. Behav. Brain Res. 1997, 83, 1-5. [CrossRef]

4. Francis, P.T.; Palmer, A.M.; Snape, M.; Wilcock, G.K. The cholinergic hypothesis of Alzheimer's disease: A review of progress. J. Neurol. Neurosurg. Psychiatry 1999, 66, 137-147. [CrossRef] [PubMed]

5. Başar, E.; Güntekin, B. A review of brain oscillations in cognitive disorders and the role of neurotransmitters. Brain Res. 2008, 1235, 172-193. [CrossRef] [PubMed]

6. Maratha, S.R.; Mahadevan, N. Memory Enhancing Activity of Naringin in Unstressed and Stressed Mice: Possible Cholinergic and Nitriergic Modulation. Neurochem. Res. 2012, 37, 2206-2212. [CrossRef] [PubMed]

7. Grober, E.; Hall, C.B.; Lipton, R.B.; Zonderman, A.B.; Resnick, S.M.; Kawas, C. Memory impairment, executive dysfunction, and intellectual decline in preclinical Alzheimer's disease. J. Int. Neuropsychol. Soc. 2008, 14, 266-278. [CrossRef] [PubMed]

8. Phelps, E.A.; Delgado, M.R.; Nearing, K.I.; LeDoux, J.E. Extinction learning in humans: Role of the amygdala and vmPFC. Neuron 2004, 43, 897-905. [CrossRef] [PubMed]

9. Pickford, F.; Masliah, E.; Britschgi, M.; Lucin, K.; Narasimhan, R.; Jaeger, P.A.; Small, S.; Spencer, B.; Rockenstein, E.; Levine, B.; et al. The autophagy-related protein beclin 1 shows reduced expression in early Alzheimer disease and regulates amyloid $\beta$ accumulation in mice. J. Clin. Investig. 2008, 118, 2190-2199. [CrossRef]

10. Goedert, M. Tau protein and the neurofibrillary pathology of Alzheimer's disease. Trends Neurosci. 1993, 16, 460-465. [CrossRef]

11. Mangialasche, F.; Solomon, A.; Winblad, B.; Mecocci, P.; Kivipelto, M. Alzheimer's disease: Clinical trials and drug development. Lancet Neurol. 2010, 9, 702-716. [CrossRef]

12. Mecocci, P.; Polidori, M.C.; Praticò, D. Antioxidant Clinical Trials in Mild Cognitive Impairment and Alzheimer's Disease. In Oxidative Stress in Applied Basic Research and Clinical Practice; Springer Science and Business Media LLC: Berlin, Germany, 2013; pp. 223-232.

13. Silva, R.; Abílio, V.; Takatsu, A.; Kameda, S.; Grassl, C.; Chehin, A.; Medrano, W.; Calzavara, M.; Registro, S.; Andersen, M.; et al. Role of hippocampal oxidative stress in memory deficits induced by sleep deprivation in mice. Neuropharmacology 2004, 46, 895-903. [CrossRef] [PubMed]

14. Rammal, H.; Bouayed, J.; Soulimani, R. A direct relationship between aggressive behavior in the resident/intruder test and cell oxidative status in adult male mice. Eur. J. Pharmacol. 2010, 627, 173-176. [CrossRef] [PubMed]

15. Stadtman, E. Free radicals in the genesis of Alzheimer's disease. Ann. N. Y. Acad. Sci. 1992, 695, 73-76. 
16. Tota, S.; Awasthi, H.; Kamat, P.K.; Nath, C.; Hanif, K.; Kamat, P.K. Protective effect of quercetin against intracerebral streptozotocin induced reduction in cerebral blood flow and impairment of memory in mice. Behav. Brain Res. 2010, 209, 73-79. [CrossRef] [PubMed]

17. Morris, M.C.; Evans, D.A.; Bienias, J.L.; Tangney, C.C.; Bennett, D.A.; Aggarwal, N.; Wilson, R.S.; Scherr, P.A. Dietary Intake of Antioxidant Nutrients and the Risk of Incident Alzheimer Disease in a Biracial Community Study. JAMA 2002, 287, 3230-3237. [CrossRef] [PubMed]

18. Chang, Y.T.; Chang, W.N.; Tsai, N.W.; Huang, C.C.; Kung, C.T.; Su, Y.J.; Lin, W.C.; Cheng, B.C.; Su, C.M.; Chiang, Y.F.; et al. The Roles of Biomarkers of Oxidative Stress and Antioxidant in Alzheimer's Disease: A Systematic Review. BioMed Res. Int. 2014, 2014, 1-14. [CrossRef]

19. Praticò, D. Evidence of oxidative stress in Alzheimer's disease brain and antioxidant therapy: Lights and shadows. Ann. N. Y. Acad. Sci. 2008, 1147, 70-78. [CrossRef]

20. Gilgun-Sherki, Y. Antioxidant Therapy in Acute Central Nervous System Injury: Current State. Pharmacol. Rev. 2002, 54, 271-284. [CrossRef]

21. Sies, H.; Stahl, W.; Sundquist, A.R. Antioxidant Functions of Vitamins: Vitamins E and C, B-Carotene, and Other Carotenoids a. Ann. N. Y. Acad. Sci. 1992, 669, 7-20. [CrossRef]

22. Nair, A.B.; Jacob, S. A simple practice guide for dose conversion between animals and human. J. Basic Clin. Pharm. 2016, 7, 27-31. [CrossRef] [PubMed]

23. Pellow, S.; Chopin, P.; File, S.E.; Briley, M. Validation of open: Closed arm entries in an elevated plus-maze as a measure of anxiety in the rat. J. Neurosci. Methods 1985, 14, 149-167. [CrossRef]

24. Vasudevan, M.; Parle, M. Memory enhancing activity of Anwala churna (Emblica officinalis Gaertn.): An Ayurvedic preparation. Physiol. Behav. 2007, 91, 46-54. [CrossRef] [PubMed]

25. Carola, V.; D'Olimpio, F.; Brunamonti, E.; Mangia, F.; Renzi, P. Evaluation of the elevated plus-maze and open-field tests for the assessment of anxiety-related behaviour in inbred mice. Behav. Brain Res. 2002, 134, 49-57. [CrossRef]

26. Walsh, R.N.; Cummins, R.A. The open-field test: A critical review. Psychol. Bull. 1976, 83, 482-504. [CrossRef] [PubMed]

27. Rahman, I.; Kode, A.; Biswas, S.K. Assay for quantitative determination of glutathione and glutathione disulfide levels using enzymatic recycling method. Nat. Protoc. 2006, 1, 3159-3165. [CrossRef] [PubMed]

28. Suh, J.H.; Wang, H.; Liu, R.M.; Liu, J.; Hagen, T.M. (R)- $\alpha$-Lipoic acid reverses the age-related loss in GSH redox status in post-mitotic tissues: Evidence for increased cysteine requirement for zGSH synthesis. Arch. Biochem. Biophys. 2004, 423, 126-135. [CrossRef] [PubMed]

29. Bin Choi, Y.; Kim, Y.I.; Lee, K.S.; Kim, B.S.; Kim, D.J. Protective effect of epigallocatechin gallate on brain damage after transient middle cerebral artery occlusion in rats. Brain Res. 2004, 1019, 47-54. [CrossRef] [PubMed]

30. Okado-Matsumoto, A.; Fridovich, I. Subcellular Distribution of Superoxide Dismutases (SOD) in Rat Liver: $\mathrm{Cu}, \mathrm{Zn}-\mathrm{SOD}$ in mitochondria. J. Biol. Chem. 2001, 276, 38388-38393. [CrossRef] [PubMed]

31. Saleem, U.; Ahmad, B.; Ahmad, M.; Hussain, K.; Bukhari, N.I. Investigation of in vivo antioxidant activity of Euphorbia helioscopia latex and leaves methanol extract: A target against oxidative stress induced toxicity. Asian Pac. J. Trop. Med. 2014, 7, S369-S375. [CrossRef]

32. Waterborg, J.H. The Lowry method for protein quantitation. In The Protein Protocols Handbook; Springer: Berlin/Heidelberg, Germany, 2002; pp. 7-9.

33. Ellman, G.L.; Courtney, K.D.; Andres, V., Jr.; Featherstone, R.M. A new and rapid colorimetric determination of acetylcholinesterase activity. Biochem. Pharmacol. 1961, 7, 88-95. [CrossRef]

34. DeMattos, R.B.; Bales, K.R.; Cummins, D.J.; Paul, S.M.; Holtzman, D.M. Brain to plasma amyloid- $\beta$ efflux: A measure of brain amyloid burden in a mouse model of Alzheimer's disease. Science 2002, 295, 2264-2267. [CrossRef] [PubMed]

35. Trott, O.; Olson, A.J. AutoDock Vina: Improving the speed and accuracy of docking with a new scoring function, efficient optimization, and multithreading. J. Comput. Chem. 2010, 31, 455-461. [CrossRef] [PubMed]

36. O’Boyle, N.M.; Banck, M.; James, C.A.; Morley, C.; Vandermeersch, T.; Hutchison, G.R. Open Babel: An open chemical toolbox. J. Chemin. Form. 2011, 3, 33.

37. Biovia, D.S. Discovery Studio Modeling Environment; Dassault Systèmes: San Diego, CA, USA, 2017. 
38. Esch, T.; Stefano, G.B.; Fricchione, G.L.; Benson, H. The role of stress in neurodegenerative diseases and mental disorders. Neuro Endocrinol. Lett. 2002, 23, 199-208. [PubMed]

39. Hira, S.; Saleem, U.; Anwar, F.; Ahmad, B. Antioxidants Attenuate Isolation- and L-DOPA-Induced Aggression in Mice. Front. Pharmacol. 2018, 8, 945. [CrossRef] [PubMed]

40. Farr, S.A.; Poon, H.F.; Dogrukol-Ak, D.; Drake, J.; Banks, W.A.; Eyerman, E.; Butterfield, D.A.; Morley, J.E. The antioxidants $\alpha$-lipoic acid and $\mathrm{N}$-acetylcysteine reverse memory impairment and brain oxidative stress in aged SAMP8 mice. J. Neurochem. 2003, 84, 1173-1183. [CrossRef]

41. Fernández-Checa, J.C.; Kaplowitz, N.; Garcia-Ruiz, C.; Colell, A.; Miranda, M.; Mari, M.; Ardite, E.; Morales, A. GSH transport in mitochondria: Defense against TNF-induced oxidative stress and alcohol-induced defect. Am. J. Physiol. Liver Physiol. 1997, 273, G7-G17. [CrossRef]

42. Kim, J.; Keum, Y.S. NRF2, a Key Regulator of Antioxidants with Two Faces towards Cancer. Oxidative Med. Cell. Longev. 2016, 2016, 1-7. [CrossRef]

43. Doroshow, J.H. Glutathione peroxidase and oxidative stress. Toxicol. Lett. 1995, 82, 395-398. [CrossRef]

44. Shahripour, R.B.; Harrigan, M.R.; Alexandrov, A.V. N-acetylcysteine (NAC) in neurological disorders: Mechanisms of action and therapeutic opportunities. Brain Behav. 2014, 4, 108-122. [CrossRef] [PubMed]

45. Finkel, T.; Holbrook, N.J. Oxidants, oxidative stress and the biology of ageing. Nature 2000, 408, $239-247$. [CrossRef] [PubMed]

46. Tiwari, V.; Kuhad, A.; Bishnoi, M.; Chopra, K. Chronic treatment with tocotrienol, an isoform of vitamin E, prevents intracerebroventricular streptozotocin-induced cognitive impairment and oxidative-nitrosative stress in rats. Pharmacol. Biochem. Behav. 2009, 93, 183-189. [CrossRef] [PubMed]

47. Ansari, M.A.; Ahmad, A.S.; Salim, S.; Yousuf, S.; Ishrat, T.; Islam, F. Selenium Protects Cerebral Ischemia in Rat Brain Mitochondria. Biol. Trace Element Res. 2004, 101, 73-86. [CrossRef]

48. Chang, Q.; Gold, E.P. Switching memory systems during learning: Changes in patterns of brain acetylcholine release in the hippocampus and striatum in rats. F1000 Post Publ. Peer Rev. Biomed. Lit. 2003, 23, 3001-3005. [CrossRef]

49. Gold, P.E. Acetylcholine modulation of neural systems involved in learning and memory. Neurobiol. Learn. Mem. 2003, 80, 194-210. [CrossRef]

50. Jarrett, J.T.; Lansbury, P.T., Jr. Seeding “one-dimensional crystallization” of amyloid: A pathogenic mechanism in Alzheimer's disease and scrapie? Cell 1993, 73, 1055-1058. [CrossRef]

51. Saleem, U.; Raza, Z.; Anwar, F.; Ahmad, B.; Hira, S.; Ali, T. Experimental and Computational Studies to Characterize and Evaluate the Therapeutic Effect of Albizia lebbeck (L.) Seeds in Alzheimer's Disease. Medicina 2019, 55, 184. [CrossRef]

52. Herholz, K. Acetylcholine esterase activity in mild cognitive impairment and Alzheimer's disease. Eur. J. Nucl. Med. Mol. Imaging 2008, 35, 25-29. [CrossRef] 